\title{
APLIKASI PENENTUAN DESAIN KURSI ERGONOMI PADA AKTIVITAS MEMBATIK UNTUK PENINGKATAN PRODUKTIVITAS
}

\author{
Wibowo Harry Sugiharto ${ }^{1)}$, Akh Sokhibi ${ }^{2)}$ \\ 1) Program Studi Teknik Informatika, Fakultas Teknik, Universitas Muria Kudus - Indonesia \\ 2) Program Studi Teknik Industri, Fakultas Teknik, Universitas Muria Kudus - Indonesia \\ Email : wibowo.harrys@umk.ac.id ${ }^{1)}$,akh.Sokhibi@umk.ac.id ${ }^{2)}$
}

\begin{abstract}
Abstrak
Produktifitas dalam aktifitas usaha menjadi sesuatu yang sangat penting, karena merupakan penentu keberlangsungan dari usaha tersebut. Banyak faktor yang mempengaruhi produktivitas suatu usaha, salah satunya adalah faktor ergonomi. Ergonomi merupakan studi tentang aspek - aspek manusia dalam lingkungan kerjanya yang ditinjau secara anatomi, fisiologi, psikologi, engineering, manajemen dan desain atau perancangan. Proses pembuatan batik yang masih tradisional masih menggunakan alat yang sederhana, perlu adanya perhatian terhadap fasilitas membatik ini sehingga proses produksi dari batik dapat berjalan dengan efisien. pengukuran anthropometrics digunakan untuk mempelajari interaksi pekerja dengan tugas, peralatan, mesin, kendaraan, dan alat pelindung diri, pengukuran anthropometrics juga dapat digunakan untuk menentukan sebuah desain kursi ergonomi pada fasilitas membatik. Paper ini menawarkan solusi dengan pendekatan berupa pengembangan aplikasi penentuan desain kursi ergonomi yang memiliki 4 tahap utama dalam prosesnya, diantaranya pengumpulan data anthropometry pembatik, pengujian data pembatik, penentuan nilai persentile, dan tahap penentuan ukuran kursi. Hasil dari implementasi menghasilkan sebuah aplikasi yang dapat menentukan desain ukuran kursi ergonomi, hasil perhitungan dapat digunakan sebagai acuan pembuatan kursi dalam fasilitas membatik untuk meningkatkan produktivitas pembatik.
\end{abstract}

Kata kunci : Ergonomi, Anthropometry, Desain Kursi.

\section{Abstract}

Productivity in business activities becomes very important because it is a determinant of business sustainability. Many factors influence the business productivity, one of them is ergonomics. Ergonomics is a study of human aspects in work environment which is reviewed anatomically, physiologically, psychologically, engineering, management, and design. The process of making batik that is still traditional use a simple tool, it is necessary to pay attention to this batik facility so that the production process of batik can run efficiently. Anthropometric measurements are used to study the interaction of workers with tasks, equipment, machines, vehicles, and personal protective equipment, anthropometric measurements can also be used to determine an ergonomic chair design in batik facilities. This paper offers a solution within application of determinating ergonomic chair design applications which has 4 main stages in process, including collection of batik anthropometric data, testing batik maker data, determining percentile value, and stage of determining the chair size. The implementation results produce an application that can determine the ergonomic chair size design, the calculation results can be used as a reference for making chairs in batik facilities to increase the productivity of batik makers.

\section{Keywords : Ergonomic, Anthropometry, Chair Design.}

\section{PENDAhUluAN}

Faktor perekonomian daerah merupakan penentu maju tidaknya daerah tersebut. Pengembangan usaha dilakukan terhadap Usaha Mikro, Usaha Kecil, dan Usaha Menengah, Pengembangan usaha meliputi fasilitas pengembangan usaha dan pelaksanaan pengembangan usaha. Fasilitas pengembangan usaha dilakukan Pemerintah dan Pemerintah Daerah, sedangkan fasilitas dilakukan dalam bidang produksi dan pengolahan pemasaran, sumber daya manusia, serta desain dan teknologi. Pengembangan usaha dengan mengembangkan jaringan usaha dan Kemitraan, melakukan usaha secara efisien, mengembangkan inovasi dan peluang pasar, memperluas akses pemasaran, memanfaatkan teknologi, meningkatkan kualitas produk dan mencari sumber pendanaan usaha yang lebih luas [1].

Produktifitas dalam aktifitas usaha menjadi sesuatu yang sangat penting, karena merupakan penentu keberlangsungan dari usaha tersebut. Banyak faktor yang mempengaruhi produktivitas suatu usaha, salah satunya adalah faktor ergonomi. Ergonomi merupakan studi tentang aspek-aspek manusia dalam lingkungan kerjanya yang ditinjau secara anatomi, fisiologi, psikologi, engineering, manajemen dan desain 
atau perancangan [2]. Ergonomi berkenaan pula dengan optimasi, efisiensi, kesehatan, keselamatan dan kenyamanan manusia di tempat kerja, di rumah, dan tempat rekreasi. Di dalam ergonomi dibutuhkan studi tentang sistem dimana manusia, fasilitas kerja dan lingkungannya saling berinteraksi dengan tujuan utama yaitu menyesuaikan suasana kerja dengan manusianya [3].

Penerapan ergonomi pada umumnya merupakan aktivitas rancang bangun ataupun rancang ulang. Hal ini meliputi perangkat keras seperti misalnya perkakas kerja [4][5][6][7], bangku kerja [8][9], platform, kursi, pegangan alat kerja [10], sistem pengendali [11][12], alat peraga [13], jalan/lorong [14], pintu [15], jendela (windows)[16] dan sebagainya. Pertimbangan ergonomi yang berkaitan dengan sikap atau posisi kerja, baik duduk ataupun berdiri merupakan suatu hal yang sangat penting. Adanya sikap atau posisi kerja yang tidak mengenakkan dan berlangsung dalam waktu yang lama, akan mengakibatkan pekerja cepat mengalami kelelahan serta membuat banyak kesalahan. Terdapat sejumlah pertimbangan ergonomi antara lain: Mengurangi keharusan operator untuk bekerja dengan sikap dan posisi membungkuk dengan frekuensi kegiatan yang sering, atau jangka waktu yang lama, pengaturan posisi kerja dilakukan dalam jarak jangkauan normal, operator tidak seharusnya duduk atau berdiri dalam waktu yang lama dengan kepala, leher, dada atau kaki dalam posisi miring, dan operator tidak seharusnya bekerja dalam frekuensi atau periode waktu yang lama dengan tangan atau lengan berada diatas level siku yang normal [17]. Proses pembuatan batik yang masih tradisional masih menggunakan alat yang sederhana seperti canting dan tempat meletakkan kain yang akan dibatik. Perlu adanya perhatian terhadap fasilitas membatik ini sehingga proses produksi dari batik dapat berjalan dengan efisien. hal tersebut belum adanya aspek ergonomi dari fasilitas batik. Perlu adanya penerapan ergonomi dalam sebuah aktivitas membatik untuk dapat meningkatkan proses produktifitas. Kursi pembatik menjadi salah satu fasilitas yang dapat diimplementasikan aspek ergonomi untuk meningkatkan produktifitas dari pembatik.

\section{LANDASAN TEORI}

\section{A. Anthropometry}

Anthropometry adalah ilmu yang mendefinisikan ukuran fisik ukuran, bentuk, dan kapasitas fungsional seseorang. Diterapkan pada pencegahan cedera kerja, pengukuran anthropometric digunakan untuk mempelajari interaksi pekerja dengan tugas, peralatan, mesin, kendaraan, dan alat pelindung diri, terutama untuk menentukan tingkat perlindungan terhadap paparan berbahaya, apakah kronis atau akut [18]. Desain yang tidak sesuai dengan pengukuran anthropometric normal dari tenaga kerja dapat menyebabkan insiden yang tidak diinginkan. Pakaian seragam dari sebuah kabin alat berat untuk seorang pekerja dapat menghasilkan titik-titik buta operator yang dapat menyebabkan kaki pekerja terluka. Panjang yang tidak memadai pada sabuk pengaman dapat menyebabkan pengendara tidak menggunakan sabuk pengaman yang disediakan, hal ini yang mempengaruhi tingkat kemungkinan korban selamat pascakecelakaan. Kecocokan alat pelindung diri yang tidak memadai tidak dapat memberikan perlindungan yang cukup bagi pekerja dari paparan kesehatan dan cedera.

Data yang ada tentang ukuran dan bentuk pekerja industri terbatas. Karena kurangnya data anthropometric untuk populasi pekerja umum, peneliti keselamatan umumnya mengandalkan data yang diambil dari studi personil militer, yang sebagian besar dikumpulkan selama 1950-an hingga 1970-an. Namun, variabilitas anthropometric yang besar ada di antara berbagai populasi tenaga kerja A.S., dan mereka sangat berbeda dari populasi militer rata-rata. Pekerja industri, seperti pertanian, sopir truk, dan petugas pemadam kebakaran, juga anthropometric sangat berbeda dari populasi sipil rata-rata [19]. Tenaga kerja yang beragam di banyak pekerjaan, serta peran baru bagi perempuan di dunia kerja, membutuhkan data ukuran tubuh untuk merancang tempat kerja, sistem, dan peralatan perlindungan pribadi yang memadai. Di masa lalu, varians dalam dimensi tubuh biasanya dilaporkan sebagai sarana dan standar deviasi untuk berbagai segmen tubuh [20]. Pendekatan ini berhasil dalam menghasilkan parameter luas untuk ukuran alat pelindung diri tetapi kurang dalam menghasilkan informasi detail yang diperlukan untuk tempat kerja, alat pelindung diri, dan desain peralatan lainnya. 


\section{METODOLOGI PENELITIAN}

\subsection{Pengambilan data anthropometry pembatik}

Data anthropometry yang diperlukan dalam penentuan desain kursi ergononomi pada aktivitas membatik diantaranya adalah Tinggi Popliteal (TP), Pantat Popliteal (PP), Lebar Pinggul (LP), Tinggi Siku Duduk (TSD) dan Tinggi Bahu Duduk (TBD).

\subsection{Pengujian data anthropometry pembatik}

Pengujian data dilakukan untuk melakukan verifikasi bahwa data yang diolah nantinya merupakan data yang sudah sesuai dalam penentuan desain kursi ergonomi pada aktivitas membatik. Beberapa tahapan Pengujian data yang dilakukan diantaranya :

\section{Uji Normalitas Data}

Pengujian normalitas data menggunakan uji Kolmogorov-Smirnov, Konsep dasar dari uji normalitas Kolmogorov-Smirnov adalah dengan membandingkan distribusi data (yang akan diuji normalitasnya) dengan distribusi normal baku. Distribusi normal baku adalah data yang telah ditransformasikan ke dalam bentuk Z-Score dan diasumsikan normal [21]. Kelebihan dari uji ini adalah sederhana dan tidak menimbulkan perbedaan persepsi di antara satu pengamat dengan pengamat yang lain.

\section{Uji Keseragaman Data}

Uji keseragaman data ini bertujuan untuk mengetahui data yang akan kita gunakan tersebut segaram atau tidak. Karena jika data yang diuji tidak seragam, maka data tersebut harus dibuang atau diganti. Data dikatakan seragam jika data berada dalam batas kontrol yang telah ditetapkan. Langkah melakukan uji keseragaman data antopometri adalah:

a. Hitung nilai rata-rata hasil pengukuran dengan formula

$$
\bar{X}=\frac{\sum \mathrm{Xi}}{n}
$$

$\bar{X}$ adalah Hasil rata-rata pengukuran dan $X i$ merupakan data pengukuran ke $i$.

$b$. Tentukan standar deviasi dengan formula

$$
\sigma=\frac{\sqrt{\sum(\mathrm{xi}-\bar{x})^{2}}}{n-1}
$$

$\sigma$ merupakan Standar deviasi dari populasi dan $n$ adalah banyaknya jumlah pengamatan [22].

c. Tentukan batas kontrol atas (BKA) dan batas kontrol bawah (BKB)

BKA dan BKB yang digunakan sebagai pembatas dibuangnya data ekstrem dengan menggunakan persamaan berikut.

$$
\begin{gathered}
B K A=+k \\
B K B=-k
\end{gathered}
$$

$\mathrm{K}$ adalah Koefisien indeks, tingkat kepercayaan memiliki tiga level diantaranya tingkat kepercayaan $0 \%$ - $68 \%$ memiliki k adalah 1, tingkat kepercayaan $69 \%$ - $95 \%$ memiliki k adalah 2 dan Tingkat kepercayaan $96 \%$ - $99 \%$ memiliki k adalah 3.

\section{Uji Kecukupan Data}

Uji kecukupan data ini bertujuan untuk menguji apakah data yang diambil sudah mencukupi dengan mengetahui besarnya nilai N'. Apabila $\mathrm{N}^{\prime}<\mathrm{N}$ maka data pengukuran dianggap cukup. Langkah uji kecukupan data anthropometry Tinggi dapat ditentukan dengan persamaan berikut: 


$$
N^{\prime}=\left[\frac{\frac{k}{s} \sqrt{N\left(\sum_{j=1}^{n=30} x_{j^{2}}\right)-\left(\sum_{j=1}^{n=30} x_{j}\right)^{2}}}{\left(\sum_{j=1}^{n=30} x_{j}\right)}\right]^{2}
$$

N' adalah jumlah pengamatan yang seharusnya dilakukan, dan s merupakan tingkat ketelitian yang yang diinginkan, s dinyatakan dalam desimal dengan ketentuan $\mathrm{k}$ bernilai 1 jika tingkat kepercayaan 0 - $68 \%$, k bernilai 2 jika tingkat kepercayaan 69 - $95 \%$ dan k bernilai 3 jika tingkat kepercayaan 96 - $99 \%$.

\subsection{Menentukan nilai persentile}

Perhitungan Percentile dilakukan untuk menentukan ukuran kursi ergonomi yang akan dibuat. Sebagai contoh Percentile 95th akan menunjukkan 95\% populasi yang berada pada atau dibawah pada ukuran tersebut, sedangkan Percentile 5th akan menunjukkan 5\% populasi akan berada pada atau dibawah ukuran itu. Adapun langkah-langkah untuk menentukan nilai persentile dari data anthropometry pembatik adalah sebagai berikut [23].

1. Untuk populasi orang dengan ukuran kecil atau pendek maka digunakan ukuran Percentile 5th

$$
P_{5}=\bar{x}-1,645 \sigma
$$

2. Untuk populasi orang dengan ukuran kecil atau pendek dan besar atau tinggi maka digunakan ukuran Percentile 50th

$$
\mathrm{P} 50=\bar{x}
$$

3. Untuk populasi orang dengan ukuran besar atau tinggi maka digunakan ukuran Percentile 95th

$$
\mathrm{P} 95=\bar{x}+1,645 \sigma
$$

\subsection{Menentukan Ukuran Kursi}

Setelah ukuran percentile dari data anthropometry pembatik didapatkan, maka langkah selanjutnya adalah menentukan ukuran kursi. Adapun langkah-langkahnya adalah sebagai berikut:

1. Tinggi kursi

Untuk menentukan ukuran tinggi kursi ergonomi pembatik, maka ditentukan dari nilai persentile tinggi popliteal.

2. Lebar Alas Kursi

Untuk menentukan ukuran lebar alas kursi ergonomi pembatik, maka ditentukan dari nilai persentile lebar pantat.

3. Panjang Alas duduk Kursi

Untuk menentukan ukuran panjang alas duduk kursi ergonomi pembatik, maka ditentukan dari nilai persentile pantat popliteal.

4. Tinggi Sandaran Siku Kursi

Untuk menentukan ukuran tinggi sandaran siku kursi ergonomi pembatik, maka ditentukan dari nilai persentile tinggi siku duduk.

5. Tinggi Sandaran Punggung Kursi

Untuk menentukan ukuran tinggi sandaran punggung kursi ergonomi pembatik, maka ditentukan dari nilai persentile tinggi bahu duduk.

\section{HASIL DAN PEMBAHASAN}

Implementasi dari aplikasi penentuan desain kursi ergonomi pada aktivitas membatik diterapkan pada web-based application dengan menggunakan bahasa pemrograman PHP dan basisdata MySQL. Hasil implementasi ini ditunjukkan pada Gambar 1, 2, dan 3. 
Data Pembatik

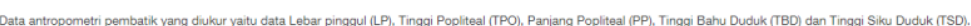
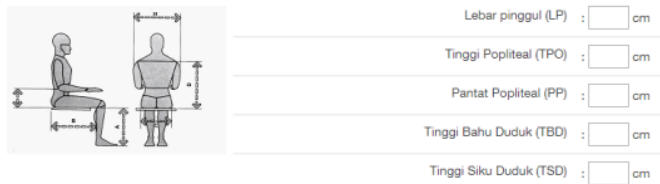

Tambah Data

\begin{tabular}{|r|c|c|c|c|c|}
\hline No & Lebar Pinggul (LP) & Tinggi Popliteal (IPO) & Pantat Popliteal (PP) & Tinggi Bahu Duduk (TBD) & Tinggi Siku Duduk (TSD) \\
\hline 1 & 42 & 37 & 48 & 55 & 24 \\
\hline 2 & 36 & 31 & 45 & 54 & 25 \\
\hline 3 & 34 & 33 & 44 & 53 & 26 \\
\hline 4 & 39 & 34 & 46 & 55 & 23 \\
\hline 5 & 39 & 32 & 44 & 53 & 28 \\
\hline
\end{tabular}

Gambar 1. Input Data Anthropometry Pembatik

SISTEM PERHITUNGAN KURSI ERGONOMI

Uji keseragaman data antropometri pembatik

\begin{tabular}{|c|c|c|c|c|c|}
\hline Pengukuran & Rata-Rata & $\sigma$ & BКА & вКв & KETERANGAN \\
\hline Lebar Pinggul (LP) & 37.97 & 2.8 & 43.77 & 32.16 & DATA SERAGAM \\
\hline Tinggi Popitteal (TPO) & 34.3 & 2.21 & 38.72 & 29.88 & DATA SERAGAM \\
\hline Pantat Popititeal (PP) & 43.47 & 2.57 & 48.6 & 38.34 & DATA SERAGAM \\
\hline Tinggi Bahu Duduk (TBD) & 55.77 & 2.87 & 61.51 & 50.02 & DATA SERAGAM \\
\hline Tingo Siku Duuuk (ISD) & 24,47 & 1,77 & 28 & 20.94 & DATA SERAGAM \\
\hline
\end{tabular}

Uji kecukupan data antropometri

\begin{tabular}{|c|c|c|c|}
\hline Pengukuran & N & N' & KETERANGAN \\
\hline Lebar Pinggu (LP) & 30 & 9 & DATA CUKUP \\
\hline Tinggi Pophiteal (TPO) & 30 & 7 & DATA CUKUP \\
\hline Pantat Popilitaal(PP) & 30 & 6 & DATA CUKUP \\
\hline Tinggi Bahu Duouk (TBD) & 30 & 4 & DATA CUKUP \\
\hline Tinggi Siku Duduk (TSD) & 30 & 8 & DATA CUKUP \\
\hline
\end{tabular}

Gambar 2. Pengujian Data Anthropometry Pembatik 
Perhitungan Presentile

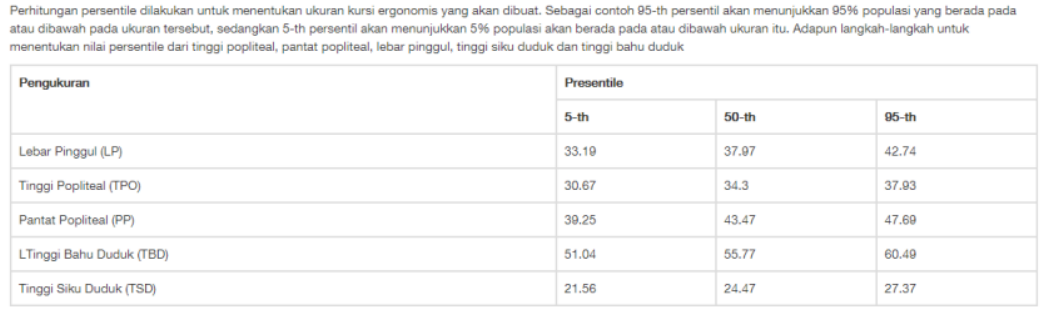

Ukuran Kursi Ergonomi

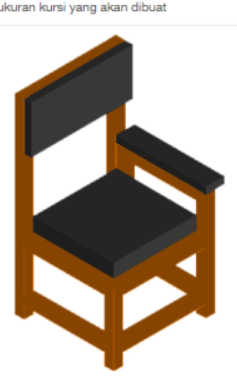

Lebar Alas Kursi : 42.74
Tinggi Kursi : 30.67 - Tinggi Kursi: 30.67
- Panjang Alas Kursi : 43.47
:- Paniagn Sandaran Pungung: 51.04
- Tinggi Alas Siku Tangag : 21.56

Gambar 3. Penentuan Presentile dan Penentuan Ukuran Kursi Ergonomi Pembatik

\section{KESIMPULAN}

Hasil dari implementasi menghasilkan sebuah aplikasi yang mampu digunakan dalam melakukan validasi terhadap data yang akan digunakan dalam melakukan perhitungan penentuan desain kursi ergonomi. Aplikasi ini juga dapat menentukan desain serta ukuran yang digunakan sebagai acuan pembuatan kursi dalam fasilitas membatik untuk meningkatkan produktivitas pembatik.

\section{DAFTAR PUSTAKA}

[1] Peraturan Pemerintah Republik Indonesia,2013, Pelaksanaan Undang-Undang Nomor 20 Tahun 2008 Tentang Usaha Mikro, Kecil, Dan Menengah, Jakarta

[2] Nurmianto, Eko, 1998, Ergonomi : Konsep Dasar dan Aplikasinya, Edisi Kedua, PT. Guna Widya, Surabaya.

[3] Santoso S. 2003, Mengolah Data Statistik Secara Profesional, PT. Elex Media Komputindo Kelompok Gramedia, Jakarta.

[4] Czerniak, J. N., Brandl, Christopher., Mertens, Alexander., 2017, Designing human-machine interaction concepts for machine tool controls regarding ergonomic requirements, IFAC PapersOnLine 50-1 (2017) 1378-1383

[5] González, A. G., Rodríguez, D. ., \& Sanz-Calcedo, J. G. , 2017, Ergonomic analysis of the dimension of a precision tool handle: a case study. Procedia Manufacturing, 13, 1336-1343. Gonzaleza, A. G., Salgado, D. S., Morunoc, L. G., 2015, Optimisation of a laparoscopic tool handle dimension based on ergonomic analysis. International Journal of Industrial Ergonomics Volume 48, July 2015, Pages 16-24

[6] Coomansa, S., Lacerda, G. S., 2015, PETESE, a Pedagogical Ergonomic Tool for Educational Software Evaluation. Procedia Manufacturing Volume 3, 2015, Pages 5881-5888

[7] Taifaa, I. W., Desaib, D. A., 2017, Anthropometric measurements for ergonomic design of students' furniture in India. Engineering Science and Technology, an International Journal Volume 20, Issue 1, 2017, Pages 232-239 
[8] Barrosa, R. Q., Marçalb, M. A., Soares, M. M., 2015, Ergonomic Analysis of the Job of Assembly and Maintenance in an Electronic Equipment Company . Procedia Manufacturing Volume 3, 2015, Pages 6542-6549

[9] Alojado, R., Custodio, B., Lasala, K. M., Marigomen, P. L., 2015, Designing an Ergonomic Chair for Pedicurists and Manicurists in Quezon City, Philippines. Procedia Manufacturing Volume 3, 2015, Pages 1812-1816

[10] Workineh, S.A., Yamaura, H., 2016, Multi-position ergonomic computer workstation design to increase comfort of computer work. International Journal of Industrial Ergonomics Volume 53, 2016, Pages 1-9

[11] Torok, L., Pelegrino, M., Trevisan, D., Montenegro, A., \& Clua, E., 2018, Smart controller: Introducing a dynamic interface adapted to the gameplay. Entertainment Computing, 27, 32-46.

[12] W, F. G., Lee, H. T., Tsai, C. J., 2018, The cognition and ergonomic design of a direct manipulation digital drawing pen for children. International Journal of Industrial Ergonomics Volume 65, 2018, Pages 161-172

[13] Bañaresa, J. R., Ann., Caballesa, S. A., Serdan, M. J., Liggayua, A. T., Bongob, M. F., 2018, A comprehension-based ergonomic redesign of Philippine road warning signs. International Journal of Industrial Ergonomics Volume 65, 2018, Pages 17-25

[14] Tak, S., Buchholz, B., Punnett, L., Moir, S., Paquet, V., Fulmer, S., Wegman, D., 2011, Physical ergonomic hazards in highway tunnel construction: Overview from the Construction Occupational Health Program. Applied Ergonomics, 42(5), 665-671.

[15] Wang, S. B., Wu, C. S., 2015, Design of the force measuring system for the hinged door: Analysis of the required operating torque. International Journal of Industrial Ergonomics Volume 49, 2015, Pages 1-10

[16] Yu, S., Lee, J., Park, B., Kim, K., \& Cho, I., 2014, Ergonomic Analysis Of A Telemanipulation Technique For A Pyroprocess Demonstration Facility. Nuclear Engineering and Technology, 46(4), 489-500.

[17] Wignjosoebroto, Sritomo, 2000, Ergonomi Studi Gerak dan Waktu : Teknik Analisis Untuk Meningkatkan Produktivitas Kerja, PT. Guna Widya, Surabaya.

[18] The National Institute for Occupational Safety and Health (NIOSH), 2016 Anthropometry

[19] Hsiao, H., Long, D., Snyder, K., 2002, Anthropometric differences among occupational groups. Ergonomics, 45(2), 136-152.

[20] Roebuck, J. A., 1975, Engineering Anthropometry Methods (Wiley Series in Human Factors). John Wiley \& Sons Inc.

[21] Hazewinkel, Michiel., 1994, "Kolmogorov-Smirnov test", Encyclopedia of Mathematics, Springer Science+Business Media B.V. / Kluwer Academic Publishers

[22] Furness, R. W., Bryant, D. M., 1996, Effect of Wind on Field Metabolic Rates of Breeding Northern Fulmars. Ecology, 77(4), 1181-1188.

[23] Fernandez, J., Goodman, M., 2000, Ergonomics In The Workplace. Publication- Solid Waste Association Of North America GR WT 235-229 
